\title{
The Effect of Bake-Hardening Parameters on the Mechanical Properties of Dual-Phase Steels
}

\author{
Ali Ramazani, 'Sonja Bruehl, Mahmoud Abbasi, Wolfgang Bleck, and Ulrich Prahl
}

Dual-phase (DP) steels offer an outstanding combination of strength and formability as a result of their microstructure, in which a hard martensitic or bainitic phase is dispersed in a soft ferritic matrix. DP steels have a high ultimate tensile strength combined with a low initial yielding stress. The yield strength of DP steels is further increased by the paint baking, also called bake hardening $(\mathrm{BH})$, process. In the current research, the effect of $\mathrm{BH}$ parameters, namely pre-strain, baking temperature, and holding time, on yield strength increment of DP steels with different martensite volume fractions is investigated. DP steels with 20 and $30 \%$ martensite volume fraction are pre-strained up to $5 \%$, then they are baked at 100,170 , and $300^{\circ} \mathrm{C}$ for various times. The results show that maximum yield strength is obtained as optimum values of $\mathrm{BH}$ parameters are applied. It is also found that at high values of baking temperature and holding time, martensite tempering effects prevail and yield strength increment decreases. The results also indicate that the increment of pre-strain enhances the Lüders band and decreases the yield strength increment.

\section{Introduction}

Recent studies have shown that in future cars DP steels can occupy up to $80 \%$ of the total weight of the car. For instance, dual-phase (DP) steels are used in the dash cross-member, B-pillar and front rail closeout. ${ }^{[-5]}$ The reason is that DP steels offer an outstanding combination of strength and ductility due to their microstructure, in which a hard martensitic phase is dispersed in a soft ferrite phase. ${ }^{[6-11]}$ DP steels consist of a ferritic matrix containing hard martensitic second phase in the form of islands. DP steels are produced by controlled cooling of specimen from the austenite phase or the two-phase range (ferrite + austenite) to transform some austenite to ferrite. In the following, the specimens are quenched to transform the remaining austenite to martensite. ${ }^{[12-16]}$ DP steels have a high ultimate tensile strength, combined with a low initial yielding stress, and high early stage strain hardening and macroscopically

[*] A. Ramazani

Department of Chemical Engineering, University of Michigan, Ann Arbor, Michigan 48109, USA

Email: ramazani@umich.edu

S. Bruehl, W. Bleck, U. Prahl

Department of Ferrous Metallurgy, RWTH Aachen University,

Intzestr.1, D-52072 Aachen, Germany

M. Abbasi

Faculty of Engineering, University of Kashan, Blvd Ravandi, Kashan, Iran

DOI: $10.1002 /$ srin.201600060 homogeneous plastic flow. ${ }^{[8]}$ These features render these steels ideal materials for automotive-related sheet forming operations.

The yield strength of DP steels is further increased by the paint baking, also called bake-hardening $(\mathrm{BH})$ process. $\mathrm{BH}$ is a controlled aging phenomenon related to the presence of carbon and/or nitrogen in solid solution in the steel. ${ }^{[17-19]}$ The BH effect is the increase in yield strength resulting from elevated temperature aging (created by the annealing temperature of paint bake ovens) after prestraining generated by the work hardening due to deformation during stamping or other manufacturing processes. ${ }^{[20-24]}$ During heating, the carbon atoms dissolved in steel, diffuse by jumping between lattice points and segregate in the regions around dislocations, and block them with a "Cottrell cloud." ${ }^{[19,25]}$ This results in locking the dislocations which is called strain aging. It is generally assumed that the $\mathrm{BH}$ effect is based on the anchoring of dislocations by carbon atoms or formation of very fine precipitates in the ferrite phase. ${ }^{[26]}$ The $\mathrm{BH}_{x}$ parameter is used to evaluate the resulting increase in yield strength. It is given by the following:

$\mathrm{BH}_{x}=\mathrm{LYS}_{x}-\mathrm{PS}_{x}$

in which $\mathrm{LYS}_{x}$ is the lower yield stress measured after heat treatment and $\mathrm{PS}_{x}$ is the yield stress after $x \%$ plastic pre-strain. The carbon content in solid solution, the existence of residual stresses, the generation of mobile dislocations at the ferrite/martensite interface, differences 


\begin{tabular}{lcccccccc}
\hline Fe & C & Si & Mn & P & S & Cr & Al & N \\
\hline Balance & 0.068 & 0.06 & 1.46 & 0.043 & 0.003 & 0.48 & 0.03 & 0.005
\end{tabular}

Table 1. Chemical composition of the investigated steel (in wt\%).

in the kinetics of strain aging of the phases, and the effect of strain partitioning between soft and hard phases can significantly affect the BH behavior of DP steels. ${ }^{[19,27]}$ These characteristics are dependent on chemical composition of the studied steel, volume fraction of constituent phases, pre-strain, baking temperature, and time.

Dehghani and Shafiei ${ }^{[28]}$ predicted the mechanical properties of baked low-carbon steels by application of an artificial neural network (ANN) model. The model considered the carbon content, the pre-strain amount, the initial yield stress, and the baking temperature as inputs and work hardening values and yield stresses after steel baking as outputs. They found that ANN model can be used to predict accurately the bake hardenability of steels. Durrenberger et al. ${ }^{[29]}$ evaluated the effect of $\mathrm{BH}$ on mechanical properties of TRIP780 steel and demonstrated that yield and tensile strengths increased as prestrain enhanced; although, the yield stress increment decreased after a certain pre-strain value. Kilic et al. ${ }^{[30]}$ studied the effects of pre-strain and temperature on $\mathrm{BH}$ treatment of TWIP900CR steel. The specimens were prestrained 2,4 , and $6 \%$ and baked at temperature of 170 and $200^{\circ} \mathrm{C}$ for $20 \mathrm{~min}$. The results showed an increase in yield strength up to $65 \mathrm{MPa}$ at the baking temperature of $200^{\circ} \mathrm{C}$ and pre-strain of $6 \%$. They found that a high baking temperature did not result in a significant increase in yield strength, and a good combination of pre-strain and baking temperature was necessary for obtaining reliable characteristics, namely work hardening, strength, and toughness for the bake-hardened twinning-induced plasticity steel.

Ramazani et al. ${ }^{[31]}$ studied the BH behavior of DP600 and TRIP700 steels for different BH conditions and found that as the $\mathrm{BH}$ temperature increased, the strengthening effect improved, due to improvement in diffusion conditions. Kuang et al. ${ }^{[32]}$ studied the effects of quenching and tempering on the $\mathrm{BH}$ behavior of DP steel. The specimens were first heated to the soaking temperature and then quenched in water and subsequently tempered in the $100-500{ }^{\circ} \mathrm{C}$ range. In the following, the specimens were pre-strained and baked at $180^{\circ} \mathrm{C}$ for $20 \mathrm{~min}$. They concluded that the carbon content, residual stresses, and free dislocations density have an important effect on the BH behavior of DP steels. They also found that with an increase in the annealing temperature, because of the dissolution of carbides, higher yield strength increment values were obtainable, and additionally increasing the quenching temperature decreased the yield strength increment value due to the relief of residual stresses during baking.
Regarding the various research carried out to study the effect of BH treatment conditions on mechanical properties of steels, in the current research, the correlation between Hollomon-Jaffe parameter and bake hardening of DP steels at different strain levels, $\mathrm{BH}$ temperatures, and times was investigated. DP steels with different martensite contents were considered. ${ }^{[33]}$

\section{Materials and Methods}

For the investigation, an industrially processed DP 500 grade with the given chemical composition (Table 1) was used. The material was delivered in $1 \mathrm{~mm}$ thickness in the as-rolled condition. After a homogenization treatment at $730{ }^{\circ} \mathrm{C}$ for $50 \mathrm{~s}$, a microstructure with $95 \%$ ferrite and $5 \%$ pearlite was detected (Figure 1). The yield strength of this material was approximately $330-350 \mathrm{MPa}$, the tensile strength was $530 \mathrm{MPa}$, and the elongation at break was given as $28-30 \%$.

Laboratory heat treatment of DP500 steel quality was performed aiming to create DP microstructure steels with 20 and $30 \%$ martensite volume fractions. A schematic view of the applied heat treatment cycles is presented in Figure 2. A homogenization treatment to dissolve carbide precipitations was followed by inter-critically annealing to get a DP steel with $30 \%$ martensite volume fraction. Preliminary examination showed that it was not possible to reach low martensite volume contents $(20 \%)$ in the microstructure after homogenization, so that the DP steel

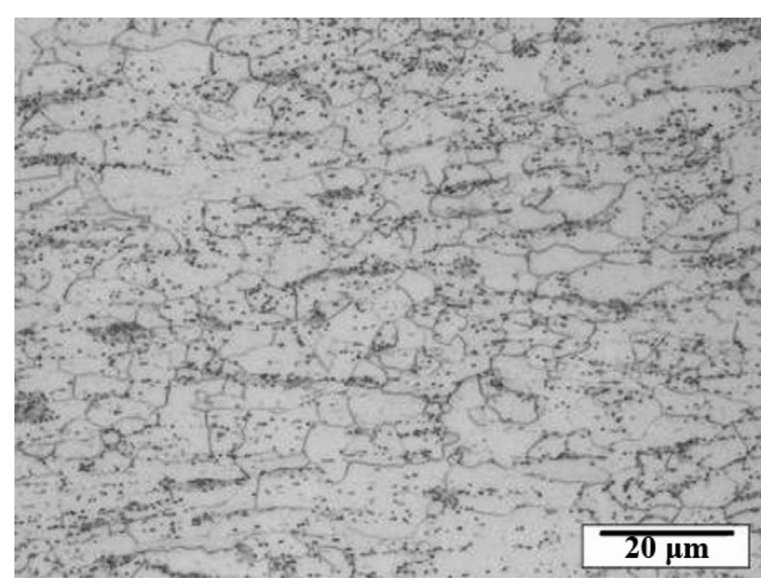

Figure 1. Microstructure of the as-received specimen after homogenization at $730{ }^{\circ} \mathrm{C}$ for $50 \mathrm{~s}$. 

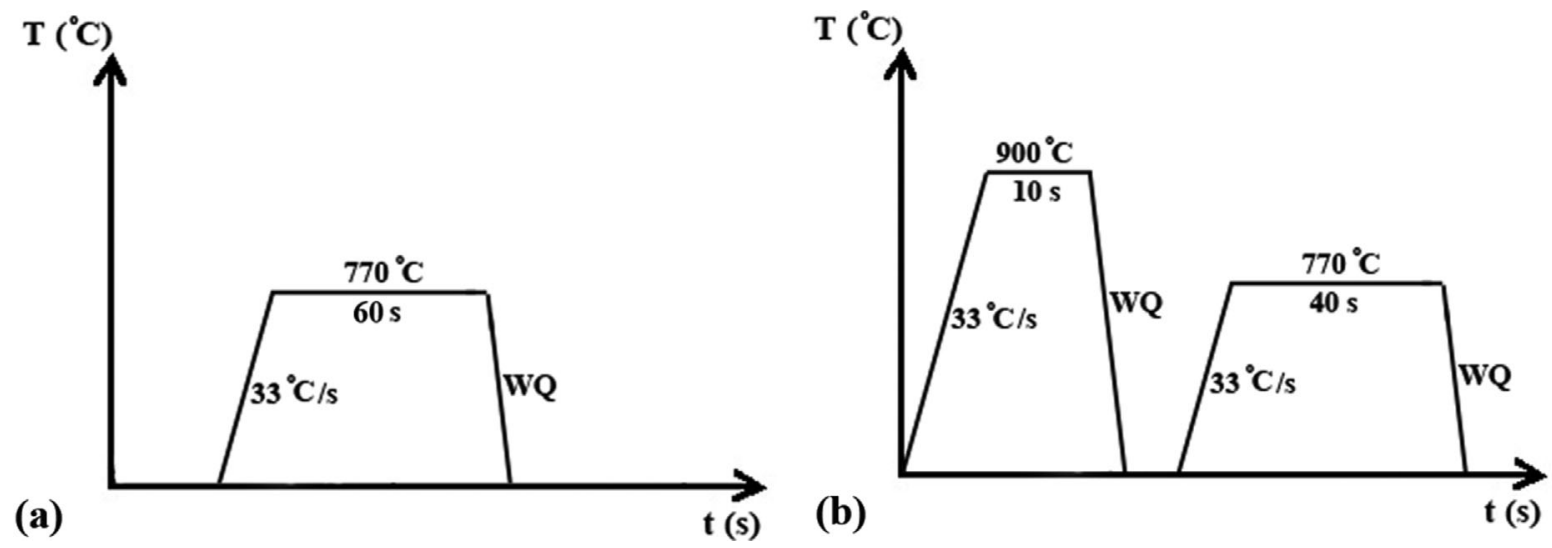

Figure 2. Heat treatment cycles were applied for preparation of DP microstructures with a) $20 \%$ martensite volume fraction; b) $30 \%$ martensite volume fraction.

with $20 \%$ martensite fraction was produced through intercritical annealing (Figure 2a).

A quantification of microstructures was carried out by standard metallographic procedures. The samples were etched by $3 \%$ Nital solution. ${ }^{[34]}$ The metallographic images were captured from the thickness direction. Tensile test samples transverse to the cold-rolling direction were prepared based on DIN EN 10002. ${ }^{[35]}$ The sample geometry used for mechanical testing is shown in Figure 3. Crosshead velocity was $4 \mathrm{~mm} \mathrm{~min}{ }^{-1}$ during tensile testing. Three samples were used for each condition.

To study the effect of the BH treatment, tensile test specimens were pre-strained initially for $0,0.5,2$, and $5 \%$ plastic strain. The samples were then unloaded and heat treated at 100,170 , and $300^{\circ} \mathrm{C}$ for $2,10,20,100,500,1000$, 5000 , and $10000 \mathrm{~min}$. After the baking treatment, the test samples were stretched again uniaxially. The tensile tests were done by a universal testing machine $\mathrm{Z} 100$ from Zwick $\mathrm{GmbH} \&$ Co. with a maximum force of $100 \mathrm{kN}$. The test power was applied through two electro-mechanic ball screws and controlling was computer-aided. During the

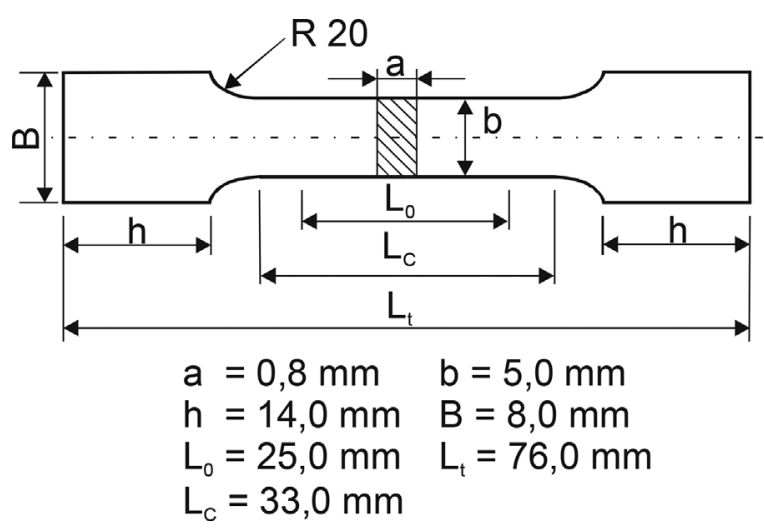

Figure 3. Design and dimensions of the tensile test specimen. tests at room temperature, the length and width variation were registered with a video extensometer. The measured values were evaluated by an accompanying software. In this way the required information, such as the yield point $R_{\mathrm{eL}}$ and the tensile strength $R_{\mathrm{m}}$ as well as the uniform and fracture strains were measured. For the calculation of the $\mathrm{BH}$ effect, the $\mathrm{BH}$ value which is defined as the difference in yield strength due to an aging treatment was used. The $\mathrm{BH}_{0}$ value describes yield strength increment of an unstrained sample in comparison to a heat-treated sample with a holding time of $20 \mathrm{~min}$ at an aging temperature of $170^{\circ} \mathrm{C}$. The $\mathrm{BH}_{x}$ value represents the strength difference from strength at a plastic strain of $x \%$ and the lower yield strength after the $\mathrm{BH}$ treatment.

\section{Results and Discussion}

The microstructures of the studied DP steels with 20 and $30 \%$ martensite volume fraction are presented in Figure 4. It is observed that the microstructure of the DP steel with $20 \%$ martensite contains a large number of carbide precipitations. This can be related to the heat treatment cycle that was applied for its production. It only consisted of inter-critical annealing without a homogenization treatment for the dissolution of carbides. In this regard, it is anticipated that the carbon concentration in the martensite phase of the DP steel with $30 \%$ martensite volume fraction would be higher than in the DP steel with $20 \%$ martensite volume fraction.

The stress-strain curves of the DP steels with the different martensite volume fractions are shown in Figure 5. As the martensite volume fraction increases, strength increases and ductility decreases. ${ }^{[36,37]}$ This can be related to the martensite effect, which is a hard and brittle phase. ${ }^{[38,39]}$ It is known that strength of DP steel depends on the volume fraction and strength of the 


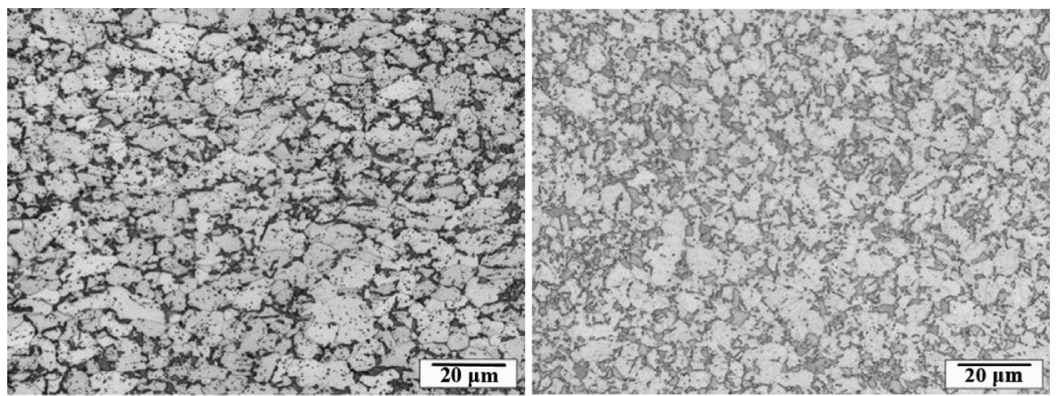

Figure 4. Microstructures of the prepared DP steels, a) DP steel with 20\% martensite volume fraction; b) DP steel with $30 \%$ martensite volume fraction.

constituent phases, namely martensite and ferrite. ${ }^{[40-42]}$ Based on the "rule of mixture," as the volume fraction of martensite increases, the strength enhances and correspondingly, ductility decreases.

Stress-strain curves of the studied DP steels, after different annealing treatment conditions, are presented in Figure 6. It is observed that for the standard baking temperature of $170^{\circ} \mathrm{C}$ and holding time of $20 \mathrm{~min}$, the Lüders band expands as the pre-strain levels up. The Lüders band, which separates the elastic region from the homogenous plastic portion of the stress-strain curve, is caused by the Cottrell effect. ${ }^{[31,43]}$ As pre-strain increases, more dislocations are generated in the ferrite phase and correspondingly more dislocations are entangled by carbon atoms that might be released from the martensite phase during baking. This results in wider Lüders bands.

As it is observed in Figure 6, the Lüders bands in 30\% martensite DP steel are wider than those in the $20 \%$ martensite material. This can also be attributed to the number of dislocations being blocked. Due to the fitting of the martensite islands in the ferrite phase during processing, the material with $30 \%$ martensite has more geometrically necessary dislocations (GNDs) at the boundary toward the ferrite phase since the distortion in the microstructure is stronger. Therefore, the Lüders bands are more pronounced. ${ }^{[31]}$

The BH effect, due to different annealing conditions, are shown in Figure 7. In this figure, the role of baking temperature and holding time is presented based on Holloman-Jaffe parameter. The Hollomon-Jaffe parameter, or HJ, describes the effect of a heat treatment at a certain time and temperature. ${ }^{[44]}$ In the Hollomon-Jaffe parameter, this exchangeability of time and temperature can be described by the following formula: ${ }^{[44]}$

$\mathrm{HJ}=T(C+\log (t))$

where $T$ is the temperature in $\mathrm{K}, t$ is time in seconds, and $C$ is a constant. Fortunately, the $\mathrm{HJ}$ values can be assigned to different annealing conditions of $T$ and $t$ to three subsequent regions in the diagram representing the different applied $\mathrm{BH}$ temperatures of 100,170 , and $300^{\circ} \mathrm{C}$.
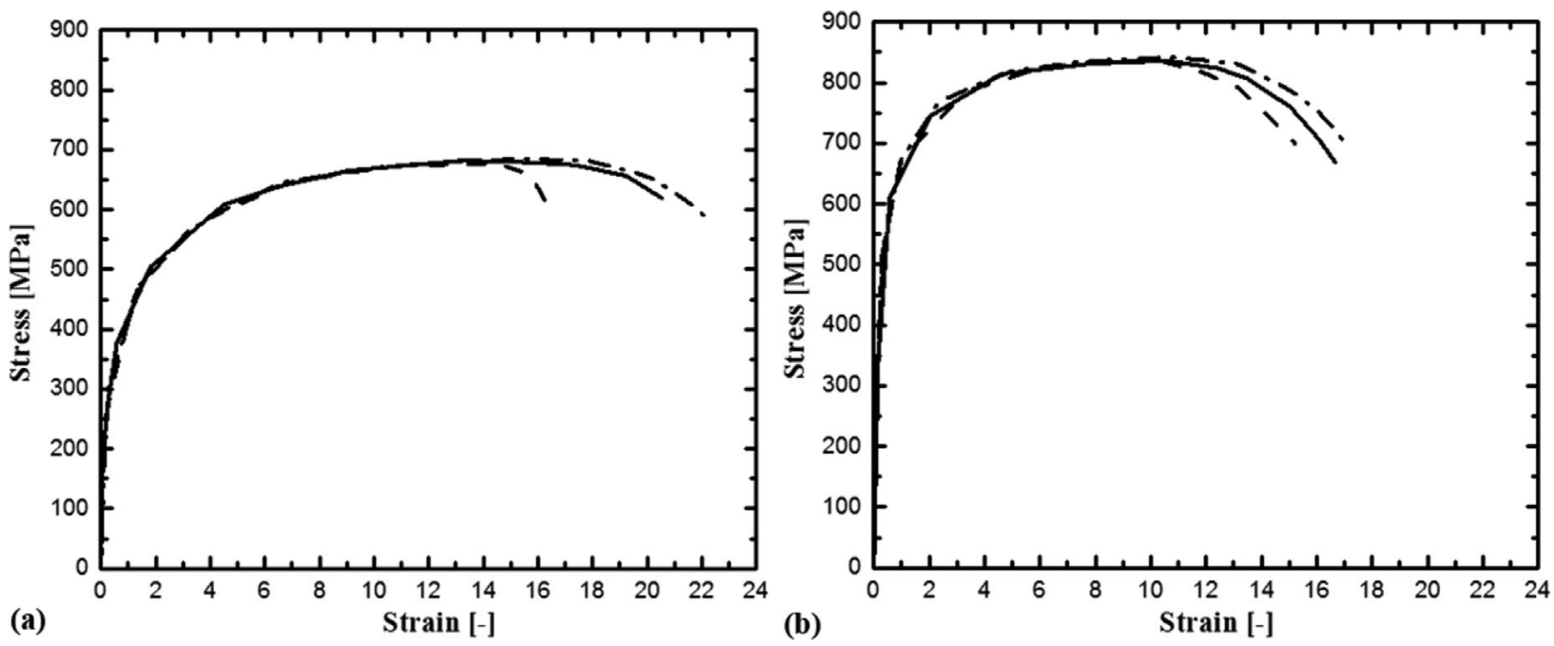

Figure 5. Stress-strain curves of prepared DP steels, a) DP steel with $20 \%$ martensite volume fraction; b) DP steel with $30 \%$ martensite volume fraction. 

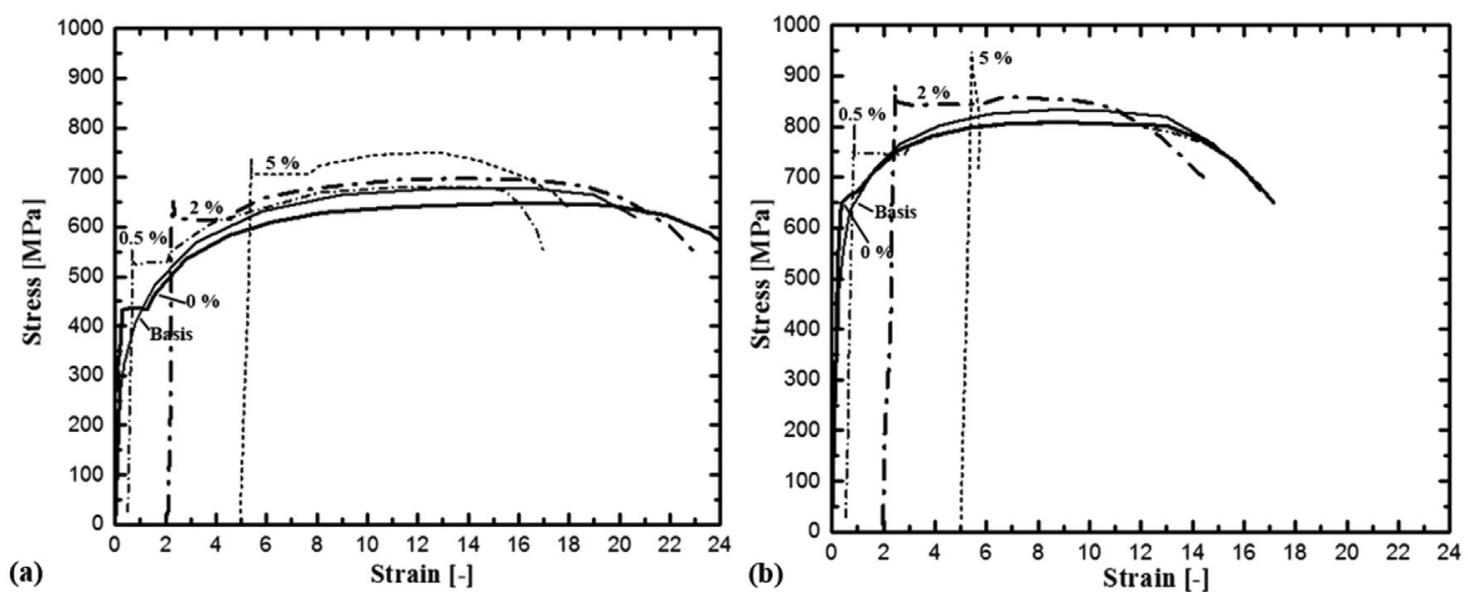

Figure 6. Stress-strain curves of DP steels with different martensite content after BH treatment, a) $20 \%$, b) $30 \%$. The specimens were all baked at $170^{\circ} \mathrm{C}$ for $20 \mathrm{~min}$. The pre-strain values are denoted for each curve.
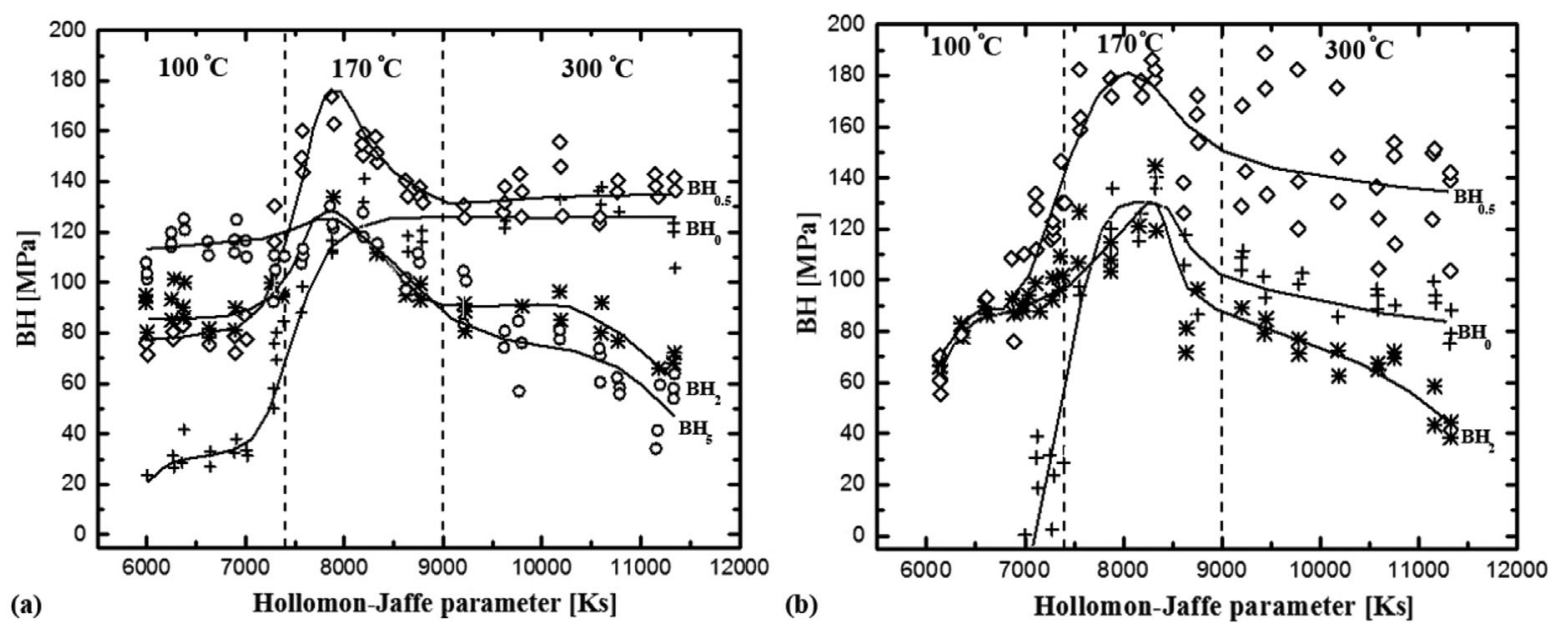

Figure 7. Yield point increase versus $\mathrm{HJ}$ parameter for DP steel with a) $20 \%$ and b) $30 \%$ martensite volume fraction. The curves are related to different values of pre-strain, $0,0.5,2$, and $5 \%$.

It is observed that for both studied DP steels, the $\mathrm{BH}$ values show an instant strength increase of 20 to $>100 \mathrm{MPa}$ for $100{ }^{\circ} \mathrm{C}$ treatments followed by a peak at about $100-$ $180 \mathrm{MPa}$ in the $170^{\circ} \mathrm{C}$ region. Higher $\mathrm{BH}$ temperatures of $300{ }^{\circ} \mathrm{C}$ cause a decrease from 120 to $40 \mathrm{MPa}$ in $\mathrm{BH}$ values again. Additionally, it is observed that for low pre-strain values, the $\mathrm{BH}$ value enhancement is significant.

It seems that at low baking temperature and holding time, the Cottrell effect is domineering. Carbon atoms are attracted toward free dislocations in the ferrite. This causes interactions between dislocation and solute atoms and correspondingly enhances the strength. ${ }^{[45]}$ In conventional $\mathrm{BH}$ steels, the Cottrell effect is limited by the available solute $\mathrm{C}$ in the microstructure. Due to the special $\mathrm{C}$ distribution in DP steels, the martensite islands serve as additional $C$ sources. $C$ atoms released from the martensite phase diffusing into the ferrite at higher $\mathrm{BH}$ conditions support the interaction effects. The Cottrell induced C localization at dislocations represent favorable nucleation sites and the additional $\mathrm{C}$ drag from martensite may form small coherent $\mathrm{C}$ precipitates which need to be cut by dislocations according to the Kelly-Fine mechanism. This causes the second strength increase due to precipitation hardening in the $170^{\circ} \mathrm{C} \mathrm{HJ}$ region at longer holding times. Following this idea of pronounced $\mathrm{C}$ diffusion effecting the precipitations may grow with higher $\mathrm{BH}$ temperatures and annealing times and, reaching a critical size, the strengthening increase will turn into overaging effects decreasing the strength again and precipitations will be bypassed using to the Orowan mechanism. Also the martensite structure may be softened during the $300{ }^{\circ} \mathrm{C}$ annealing treatment.

According to Naderi et al. ${ }^{[46]}$ and Ramazani et al., ${ }^{[47,48]}$ the high strength of martensite is dependent on 
dislocations, elastic stresses, twin boundaries, and the solid solution strengthening by the carbon atoms. During the tempering, due to the release of elastic distortions and the tangled carbon atoms as well as the annihilation of dislocations, the martensite strength $\left(\sigma_{\mathrm{m}}\right)$ decreases. Regarding "the rule of mixture," it seems that for very high values of the $\mathrm{HJ}$ parameter, the softening effect due to tempering is higher than the hardening effect due to the Cottrell effect and precipitation effects.

It is also observed in Figure 7 that samples of $0.5 \%$ prestrain have an observable $\mathrm{BH}$ increase as the $\mathrm{HJ}$ parameter increases, while for samples pre-strained 2 or $5 \%$ the $\mathrm{BH}$ increase versus $\mathrm{HJ}$ parameter is low. For the $0.5 \%$ pre-strain, it seems that an optimum relation of $\mathrm{C}$ atoms and dislocations exists in the microstructure. The dislocations are homogeneously distributed in the ferrite grains and diffusion and precipitation processes occur, so that maximal $\mathrm{BH}$ values $>150 \mathrm{MPa}$ are reached. In the unstrained state, there are rarely any precipitation sites available. For higher pre-strains, dislocation interactions, and network formation reduce precipitation sites as well. Additionally, a higher driving force for the homogenization of the microstructure and reduction of inner tensions as a tendency of the material to lower its free energy may cause an overall softer microstructure and thus lower strength values appear.

\section{Conclusions}

In the current research, the effect of $\mathrm{BH}$ treatment parameters, namely pre-strain, baking temperature, and holding time, on mechanical properties of DP steels with different martensite volume fractions of 20 and $30 \%$ was considered. The results showed that Lüders bands appear in stress-strain curves after the conventional BH treatment $\left(170^{\circ} \mathrm{C}\right.$ for $20 \mathrm{~min}$ ) and it expands as the pre-strain values are increased. The pre-straining induces free dislocations into the microstructure being blocked by $\mathrm{C}$ atoms according to the Cottrell effect. So the Lüders bands get longer with higher pre-straining degrees. The same effect may explain pronounced Lüders bands in the $30 \%$ martensite material due to the higher number of dislocations in the strongly distorted microstructure.

It can be concluded that the $\mathrm{BH}$ behavior depends on the one hand on material inherent parameters as microstructural features of the martensite islands, the distribution of dislocations, and the $\mathrm{C}$ content in the different phases. On the other hand, the $\mathrm{BH}$ parameters such as annealing temperature, holding time, and pre-straining conditions are decisive for the $\mathrm{BH}$ effects. An optimum combination of the both results in maximum $\mathrm{BH}$ values of $>170 \mathrm{MPa}$ strength increase. The material behavior resulting from different $\mathrm{BH}$ conditions is displayed in comparison using the $\mathrm{HJ}$ parameter. The transitions between the temperature regions of the $\mathrm{BH}$ treatment are continuous in the diagram, so the mechanisms can be interpreted as consecutive.
Three aging stages can be defined for DP steels: The first stage of aging is ruled, as known from conventional $\mathrm{BH}$ steels, by the formation of Cottrell atmospheres. C atoms segregate at dislocations thus blocking their movement and increasing the strength. In the second aging stage, $\mathrm{C}$ diffusion from martensite island into the ferrite is activated, so precipitation effects can occur additionally. The chemical composition and microstructure of DP steels deliver a rich source of $\mathrm{C}$ atoms as to enable both mechanisms, Cottrell and precipitation hardening, to be active simultaneously. During the third stage, overaging of precipitations in combination with martensite tempering causes a strength decrease again.

\section{Acknowledgement}

The authors acknowledge the financial support from DFG within the Project "BL 402/36_1."

Received: February 23, 2016; Revised: June 2, 2016; Published online: June 27, 2016

Keywords: bake-hardening; dual-phase steel; HollomonJaffe parameter; Lüders band

\section{References}

[1] WorldAutoSteel, Ultra-Light Steel Auto BodyAdvanced Vehicle Technology (ULSABAVC) Programme, Overview Report, January 2002.

[2] A. Ramazani, B. Berme, U. Prahl, in Structural Materials and Processes in Transportation (Eds: D. Lehmhus, M. Busse, A. S. Herrmann, K. Kayvantash), Wiley-VCH, Singapore 2013, 5.

[3] W. Bleck, S. Papaefthymiou, A. Frehn, Steel Res. Int. 2004, 75, 704.

[4] R. Ruziak, R. Kawalla, S. Wangler, Arch. Civil Mech. Eng. 2008, 8, 103.

[5] B. K. Zuidema, S. G. Denner, B. Engl, J. Sperle, Soc. Auto. Eng. 2011, 984.

[6] P. H. Chang, A. G. Preban, Acta Metall. 1985, 33, 897.

[7] P. Tsipouridis, $P h D$ Thesis, Technical University of Muenchen, Germany 2006.

[8] A. Ramazani, K. Mukherjee, A. Abdurakhmanov, U. Prahl, M. Schleser, U. Reisgen, W. Bleck, Mater. Sci. Eng. A 2014, 589, 1.

[9] C. Thomser, V. Uthaisangsuk, W. Bleck, Steel Res. Int. 2009, 80, 582.

[10] M. Calcagnotto, Y. Adachi, D. Ponge, D. Raabe, Acta Mater. 2011, 59, 658.

[11] J. Y. Kang, H. C. Lee, S. H. Han, Mater. Sci. Eng. A 2011, 530, 183.

[12] A. Ramazani, Z. Ebrahimi, U. Prahl, Comput. Mater. Sci. 2014, 87, 241.

[13] N. Saeidi, F. Ashrafizadeh, B. Niroumand, Mater. Sci. Eng. A 2014, 599, 145. 
[14] J. Hu, L. X. Du, J. J. Wang, C. R. Gao, T. Z. Yang, A. Y. Wang, R. D. K. Misra, Metall. Mater. Trans. A 2013, 44, 4937.

[15] V. L. Concepción, H. N. Lorusso, H. G. Svoboda, Procedia Mater. Sci. 2015, 8, 1047.

[16] A. Ramazani, Y. Chang, U. Prahl, Adv. Eng. Mater. 2014, 16, 1370.

[17] I. B. Timokhina, P. D. Hodgson, E. V. Pereloma, Metall. Mater. Trans. A 2007, 38, 2442.

[18] T. Waterschoot, A. K. De, S. Vandeputte, B. C. De Cooman, Metall. Mater. Trans. A 2003, 34, 781.

[19] I. B. Timokhina, E. V. Pereloma, S. P. Ringer, R. K. Zheng, P. D. Hodgson, ISIJ Int. 2010, 50, 574.

[20] A. Ramazani, K. Mukherjee, A. Abdurakhmanov, M. Abbasi, U. Prahl, Metals 2015, 5, 1704.

[21] R. O. Rocha, T. M. F. Melo, E. V. Pereloma, D. B. Santos, Mater. Sci. Eng. A 2005, 391, 296.

[22] M. Naderi, M. Ketabchi, M. Abbasi, W. Bleck, J. Mater Process. Technol. 2011, 211, 1117.

[23] A. Ramazani, P. Pinard, A. Schwedt, S. Richter, U. Prahl, W. Bleck, Comput. Mater. Sci. 2013, 80, 134.

[24] A. Ramazani, Y. Li, U. Prahl, K. Mukherjee, W. Bleck, U. Reisgen, M. Schleser, A. Abdurakhmanov, Comput. Mater. Sci. 2013, 68, 107.

[25] G. E. Dieter, Mechanical Metallurgy, McGraw-Hill, Singapore 1988.

[26] W. Bleck, Material Science of Steel, Textbook for RWTH students, Verlag Mainz, Aachen 2010.

[27] Q. Lai, O. Bouaziz, M. Gouné, L. Brassart, M. Verdier, G. Parry, A. Perlade, Y. Bréchet, T. Pardoen, Mater. Sci. Eng. A 2015, 646, 322.

[28] K. Dehghani, A. Shafiei, Mater. Lett. 2008, 62, 173.

[29] L. Durrenberger, X. Lemoine, A. Molinari, J. Mater. Process. Technol. 2011, 211, 1937.

[30] S. Kilic, F. Ozturk, T. Sigirtmac, G. Tekin, Int. J. Iron Steel Res. 2015, 22, 361.

[31] A. Ramazani, S. Bruhl, T. Gerber, W. Bleck, U. Prahl, Mater. Des. 2014, 57, 479.
[32] C. F. Kuang, J. Li, S. G. Zhang, J. Wang, H. F. Liu, A. A. Volinsky, Mater. Sci. Eng. A 2014, 613, 178.

[33] S. Bruhl, Ph.D. Thesis, IEHK-RWTH Aachen, Germany 2011.

[34] C. Thomser, Ph.D. Thesis, IEHK-RWTH Aachen, Germany 2009.

[35] DIN EN10002, Metallic Materials - Tensile Testing-Part 1: Method of Testing at Ambient Temperature, German version EN 10002-1, 2001.

[36] A. Ramazani, K. Mukherjee, U. Prahl, W. Bleck, Metall. Mater. Trans. A 2012, 43, 3850.

[37] A. Ramazani, K. Mukherjee, A. Schwedt, P. Goravanchi, U. Prahl, W. Bleck, Int. J. Plast. 2013, $43,128$.

[38] X. Sun, K. S. Choi, W. N. Liu, M. A. Khaleel, Int. J. Plast. 2009, 25, 1889.

[39] A. Ramazani, A. Schwedt, A. Aretz, U. Prahl, Key Eng. Mater. 2014, 586, 67.

[40] M. Calcagnotto, D. Ponge, E. Demir, D. Raabe, Mater. Sci. Eng. A 2010, 527, 2738.

[41] R. K. Abu Al-Rub, M. Ettehad, A. N. Palazotto, Int. J. Solids Struct. 2015, 58, 178.

[42] A. Ramazani, K. Mukherjee, U. Prahl, W. Bleck, Comput. Mater. Sci. 2012, 52, 46.

[43] R. W. Hertzberg, Deformation and Fracture Mechanics of Engineering Materials, John Wiley \& Sons, Canada 1989.

[44] V. N. Zikee, Y. V. Kornyushchenkova, V. V. Izvolskii, Constr. Steels 1984, 26, 99.

[45] D. Hull, D. J. Bacon, Introduction to Dislocations, Butterworth-Heinemann, London 2011.

[46] M. Naderi, M. Abbasi, A. Saeed Akbari, Metall. Mater. Trans. A 2013, 44, 1852.

[47] A. Ramazani, M. Abbasi, S. Kazemiabnavi, S. Schmauder, R. Larson, U. Prahl, Mater. Sci. Eng. A 2016, 660, 181.

[48] A. Ramazani, A. Schwedt, A. Aretz, U. Prahl, W. Bleck, Comput. Mater. Sci. 2013, 75, 35. 